\title{
O ENSINO DE MATEMÁTICA SEGUNDO ESTUDANTES CEGOS DE BELÉM DO PARÁ 1
}

\author{
Sandy da Conceição Dias² \\ Pedro Franco de Sá ${ }^{3}$ \\ Maria de Lourdes Silva Sant os 4
}

\section{RESUMO}

Este trabalho apresenta os resultados de uma pesquisa que teve como objetivo realizar um diagnóstico do processo de ensino e aprendizagem de matemática, no $6^{\circ}$ ano para estudantes cegos de Belém do Pará. A produção das informações ocorreu por meio de entrevista semiestruturada, realizada junto a seis estudantes cegos. As análises indicaram que apesar dos av anços na legislação, os estudantes ainda não se encontravam devidamente incluídos em sala, e que a metodologia adotada pelos professores nas aulas, eram preponderantemente expositivas, desconsiderando as necessidades de aprendizagem e condição de estudantes cegos, fato que comprometia a aprendizagem, sobretudo, nas aulas cujos conteúdos envolviam gráficos e assuntos da geometria espacial. Em relação aos assuntos do $6^{\circ}$ ano, considerados os mais difíceis para os estudantes cegos aprenderem, eles indicaram os seguintes: Expressões numéricas; Divisão não exata; Simplificação de Fração, Potenciação e Radiciação; Ângulos; Segmento de retas; Tipos de gráficos, entre outros. A pesquisa nos permitiu concluir que o processo de inclusão de estudantes cegos, especialmente, no que concerne a disciplina matemática, ainda está longe das condições apropriadas para eles, sobretudo, se considerarmos as reclamações feitas pela amostra relacionadas ao fato de que dependiam muito da ajuda de terceiros para estudarem e registrarem suas atividades escolares indicando que estes estudantes estav am inseridos nas turmas regulares, mas não necessariamente incluídos no processo educacional.

Palavras-chave: Educação Matemática. Educação Especial. Ensino de Matemática para Cego.

\footnotetext{
1 O presente trabalho foi realizado com apoio da Coordenação de Aperfeiçoamento de Pessoal de Nível Superior- Brasil (CAPES) - Código de Financiamento 001.

2Mestre em Educação pela Universidade do Estado do Pará (UEPA). Pós-Graduada em Educação Especial com Ênfase na Inclusão pela Faculdade Integrada Brasil Amazônia (FIBRA). ORCID iD: https://orcid.org/0000-0003-2714-0372. E-mail: sandydias_13@yahoo.com.br

3Doutor em Educação pela Universidade Federal do Rio Grande do Norte (UFRN). Professor Titular em Educação Matemática na Universidade do Estado do Pará. Membro dos Programas de Educação e do Mestrado Profissional em Ensino de Matemática da Universidade do Estado do Pará e Docente da REAMEC. ORCID iD: https://orcid.org/00000002-8986-2787. E-mail: pedro.franco.sa@gmail.com

4Doutora em Educação pela Pontifícia Universidade Católica do Rio de Janeiro (PUC-RIO). Professora Adjunta na Universidade do Estado do Pará. Docente do mestrado profissional em Ensino de Matemática da Universidade do Estado do Pará. ORCID iD: https://orcid.org/00000003-2808-4536 E-mail: 2011.malu.melo@gmail.com
}

Revista Exitus, Santarém/PA, Vol. 9, № 3, p. 223 - 251, JUL/SET 2019. 


\title{
THE TEACHING OF MATHEMATICS ACCORDING TO BLIND STUDENTS FROM BELÉM, STATE OF PARÁ
}

\begin{abstract}
This work presents the results of a study aimed at making a diagnosis of the teaching and learning process of mathematics in Year 6 for blind students of Belém, state of Pará. Data were gathered through a semistructured interview conducted with six blind students. The analysis indicated that, despite the advances in the legislation, the students were not yet properly included in the classroom, and that the methodology adopted by the teachers in the classes were preponderantly expositive, disregarding the learning needs and the condition of blind students, a fact that compromised learning, especially in classes whose content involved graphics and spatial geometry. Regarding the Year-6 subjects to be considered the most difficult ones for blind students to learn, they indicated the following: Number expressions; Not accurate division; Fraction Simplification, Potentiation and Radiation; Angles; Line segment; Types of graphs, among others. The research allowed us to conclude that the process of including blind students, especially regarding mathematical discipline, is still far from the appropriate conditions for them, especially considering the complaints made by the sample related to the fact that they depended heavily on the help of third parties to study and record their school activities indicating that these students were included in regular classes but not necessarily included in the educational process.
\end{abstract}

Keywords: Mathematical Education. Special education. Math Teaching for the Blind.

\section{LA ENSEÑANZA DE MATEMÁTICA SEGÚN ESTUDIANTES CEGOS DE BELÉM DEL \\ PARÁ}

\section{RESUMEN}

Este trabajo presenta los resultados de una investigación que tuvo como objetivo realizar un diagnóstico del proceso de enseñanza y aprendizaje de matemáticas, enel sexto año para estudiantes ciegos de Belém do Pará. La producción de las informaciones ocurrió por medio de una entrevista semiestruturada realizada junto a seis estudiantes ciegos. Los análisis indicaron que a pesar de los avances en la legislación, los estudiantes aún no se encontraban debidamente incluídos em la sala, y que lametodología adoptada por los professores en las aulas eran preponderantemente expositivas, desconsiderando las necesidades de aprendizaje y condición de estudiantes ciegos, hecho que comprometía el aprendizaje, sobre todo, en las clases cuyos contenidos envolvían gráficos y asuntos de la geometría espacial. Encuanto a los assuntos del sexto año considerados los más difíciles para los estudiantes ciegos aprender, el los indicaron los siguientes: Expresiones numéricas; División no exacta; Simplificación de Fracción, Potenciación y Radiación; ángulos; Segmento de rectas; Tipos de gráficos, entre otros. La investigación nos permitió concluir que el proceso de inclusión de estudiantes ciegos, especialmente, en lo que concierne a la disciplina matemática, todavía, está lejos de las condiciones apropiadas para ellos, sobre todo, si consideramos las reclamaciones 
hechas por la muestra relacionadas al hecho de que dependían mucho de la ayuda de terceros para estudiar y registrar sus actividades escolares indicando que estos estudiantes estaban insertados em las clases regulares, pero no necessariamente incluídos enel proceso educativo.

Palabras clave: Educación Matemática. Educación Especial. Enseñanza de Matemáticas para Ciego.

\section{INTRODUÇÃO}

Inúmeros foram os caminhos percorridos para que pessoas com deficiência tivessem direito a educação e inclusão social. Desde o século passado, leis foram criadas e/ou reescritas para que elas tivessem oportunidade de frequentar o ensino regular, pois, qualquer alteração ou ausência biológica, era considerada como motivo para pessoas com deficiência não frequentassem as escolas, como também thes eram negadas oportunidades no mundo do trabalho. Ao deficiente era subtraído o direito de ser cidadão como todos nós, só que, com algumas peculiaridades mais aparentes.

Dentre os vários grupos de pessoas com deficiência, estão aquelas com deficiência visual, ou seja, com limitação de uma das formas de apreensão de informações do mundo externo. Estes indivíduos podem ser encontrados em dois grupos: baixa visão ou cegos. Por entendermos que o termo deficiente visual ser bem mais abrangente que cego, demarcarmos nossa opção pelo termo cego, sem nenhuma intenção pejorativa ou preconceituosa.

Durante muito tempo, pessoas cegas ficaram alijados do processo educacional, no entanto, a luta em prol da inclusão tem crescido e dado nova configuração para essa realidade, seja em outros contextos, seja aqui no Brasil. Apesar dos avanços, muito ainda precisa ser revisto, repensado e criado quando se fala na inclusão de estudantes com cegueira. Vieira e Silva (2007) advertem que não devemos apenas lutar para incluí-los, mas, verificar de que maneira a inclusão está sendo realizada, como as pessoas estão sendo incluídas nas salas regulares de ensino. 
A motivação para realização do estudo ocorreu por nossa área de atuação, e pelo desejo de sabermos como estudantes cegos estão estudando matemática, visto o histórico dos relatos de estudantes videntes que consideram esta disciplina uma das mais difíceis do currículo escolar, condição que certamente se agrava, quando falamos de uma Educação Matemática voltada para os cegos. Para eles, a ausência de um dos principais canais de comunicação usados, tradicionalmente, no processo de ensino e aprendizagem, ou seja, a visão. Motivou-nos a ouvir estudantes cegos, dando-lhes oportunidade de relatarem suas experiências discentes, manifest ando situações que vivenciam diariamente. Segundo Caiado (2014, p.48) "devemos dar voz aos excluídos da escola porque as pessoas com deficiência estão, historicamente, fora da escola e na condição de excluídos - eles pouco, ou nunca, falam. Alguém, geralmente, fala e decide por eles.".

A partir do estudo de Dias e Sá (2017) que consultaram professores com experiência de ensinar matemática a estudantes cegos, sentimos necessidade de, em nossa pesquisa, ouvir estudantes cegos buscando saber suas experiências como discentes, como os professores thes ensinavam matemática, quais recursos didáticos eram utilizados e quais assuntos eles tinham mais dificuldades em aprender. Nossa intenção foi aprofundar conhecimentos sobre o ensino de matemática para cegos.

Assim, este trabalho apresenta os resultados de uma pesquisa que teve como objetivo realizar um diagnóstico do processo de ensino e aprendizagem de matemática no $6^{\circ}$ ano, para estudantes cegos de Belém do Pará.

\section{ESTUDOS SOBRE O ENSINO DE MATEMÁTICA PARA CEGOS}

Em Dias e Sá (2017) encontramos os resultados de um diagnóstico do ensino e aprendizagem de matemática para deficientes visuais, a partir da opinião de professores. As informações foram produzidas por meio de entrevistas junto a 12 professores com experiência no ensino de matemática, para deficientes visuais em escolas das redes públicas, municipal e privada 
de Belém-PA. A conclusão do estudo apontou que: a maior parte dos professores consultados não era formada em Matemática; os recursos mais utilizados eram materiais concretos; o Braille ainda era muito utilizado para o registro das atividades. Entre os assuntos mais difíceis para os estudantes cegos aprenderem no $6^{\circ}$ ano destacava-se: Subtração de frações com denominadores diferentes; Potenciação e Radiciação; Resolver problemas em que se conhece uma parte e se deseja conhecer a outra parte e Tipos de gráficos.

Uliana (2013) objetivou analisar o movimento da educação inclusiva, das escolas rondonienses e diagnosticar como estava acontecendo o processo de ensino e de aprendizagem de matemática, para os estudantes cegos do Estado. Como metodologia utilizou a pesquisa qualitativa, com depoimentos orais temáticos, no caso, uma modalidade da História Oral. Os sujeitos da pesquisa foram três estudantes cegas de escolas públicas de Rondônia, uma do ensino fundamental regular, outra no primeiro ano do ensino médio e a terceira do ensino fundamental, na Educação de Jovens e Adultos, além de dois professores de matemática. A análise permitiu concluir que as alunas estavam inseridas no ensino regular, mas não thes eram dadas as devidas condições para aprendizagem, condições estas que perpassavam pelos materiais pedagógicos não adaptados, falta de estrutura da escola, currículo que respeitasse o seu nível e tempo de aprendizagem, professores sem a devida preparação para atender as peculiaridades desses estudantes o que os deixava desconfortáveis com a situação de ensinar matemática. A autora concluiu que: as alunas cegas estavam sendo prejudicadas na aprendizagem de matemática; os professores não estavam preparados para lidar com a inclusão dos estudantes cegos; os livros didáticos não estavam em Braille o que prejudicava o acesso delas aos gráficos e figuras matemáticas; falta de materiais pedagógicos adaptados.

Uliana (2015) investigou como uma disciplina/curso de formação de futuros professores de Matemática, Física ou Química, centrada em estratégias de ensino a estudantes com deficiência visual, poderia contribuir 
para a preparação docente, tendo em vista, a promoção do ensino inclusivo. Como metodologia utilizou a pesquisa-ação orientada pela abordagem qualitativa. Ao término do estudo, concluiu-se que os principais fatores que corroboram para dificultar a efetivação da inclusão de estudantes com deficiência visual nas aulas de matemática são: falta de preparo dos professores; inexistência de materiais didáticos que atendam as demandas dos estudantes com deficiência visuais; a inacessibilidade aos conteúdos dos livros didáticos; o pensamento equivocado dos professores sobre a capacidade de aprendizagem das pessoas com deficiência e o fato de os profissionais das salas de recurso, nem sempre trabalharem em parceira com o professor da classe.

Cerva Filho (2014) investigou o ensino de matemática a um aluno cego em uma classe regular do Ensino Médio, na perspectiva da Educação Inclusiva. Buscou responder como se desenvolve o processo de ensino da Matemática com um aluno cego, em uma classe regular do Ensino Médio? Como abordagem metodológica optou pela qualitativa. Como objetos de análises, utilizou os conteúdos das entrevistas e os dados produzidos durante as observações realizadas nas aulas de matemática de uma classe regular. Os sujeitos foram professores da rede municipal de ensino de Sapucaia do Sul/RS que possuíam estudantes deficientes visuaisfrequentando a educação básica, professora da sala de recursos multifuncionais e um aluno cego da rede municipal de ensino.

Ao final do estudo Cerva Filho (2014) concluiu que ações docentes influenciam o processo de aprendizagem da matemática, entre elas: a utilização de expressões e verbalismos e o posicionamento corporal. Concluiu também que: os professores não se sentiam preparados para trabalhar com estudantes que apresentam alguma necessidade especial; a carência de materiais acessiveis; a necessidade de formação docente, focadas às particularidades presentes da deficiência visual; que os profissionais do AEE tenham mais proximidade com os professores das salas regulares; o corpo docente deve prever no planejamento escolar, a 
utilização de materiais concretos manipuláveis; a necessidade de materiais transcritos para o Braille com antecedência.

Com base nas pesquisas, nos sentimos motivados a saber se as dificuldades presentes em outros contextos, também ocorrem em escolas publicas de Belém do Pará, dando continuidade a uma investigação realizada junto a uma amostra de professores de matemática que já tinham ministrado aulas para estudantes cegos, Dias e Sá (2017). Com o intuito de aprofundar mais o estudo, desta vez, optamos por ouvir estudantes cegos para obter mais informações sobre processo de ensino e aprendizagem de matemática no $6^{\circ}$ ano, de modo a termos uma visão do ensino e das dificuldades de aprendizagens deles.

\section{METODOLOGIA}

Em busca de alcançar o nosso objetivo de pesquisa, traçamos algumas etapas para o estudo sendo elas: elaboração do roteiro de atividade; entrevistas com estudantes cegos; transcrição das entrevistas e análise das informações.

\section{Elaboração do roteiro de entrevista}

Com base na revisão bibliográfica e no objetivo de pesquisa, elencamos três eixos temáticos que nortearam a elaboração do roteiro de entrevista:

1- Informações Pessoais sobre: idade, vida do estudante fora da escola, se ele/ela possuía incentivo da família para estudar, entre outros.

2- Informações Escolares: vida escolar, qual ano estava cursando, que tipo de escola que frequentavam o ensino fundamental, e assim por diante.

3- Ensino e Aprendizagem em Matemática: subdividimos em cinco subeixos para melhor analisarmos as informações: Características das aulas de matemática; Registro e Acesso; Avaliação; Materiais e Recursos; Assuntos do $6^{\circ}$ ano mais difíceis para ele/ela aprenderem. 
O instrumento totalizou 20 perguntas, as quais estão descritas no Quadro 1.

QUADRO 1 - Perguntas do roteiro de entrevistas

\begin{tabular}{|c|c|c|}
\hline \multicolumn{3}{|c|}{ Perguntas do roteiro de entrevistas } \\
\hline & Gênero? & 11) Se sim, onde acontecia esse acompanhamento? \\
\hline & Qual a sua idade? & $\begin{array}{l}\text { 12) Dentre as opções quais você considera mais difícil } \\
\text { para realizar durante as aulas de matemática: Registrar } \\
\text { o que esta estava sendo ensinado; Construir as } \\
\text { imagens mentalmente das figuras, gráficos; O tempo } \\
\text { disponibilizado para resolver as atividades. }\end{array}$ \\
\hline & $\begin{array}{l}\text { Você tem incentivo da sua família para } \\
\text { estudar? }\end{array}$ & $\begin{array}{l}\text { 13) Como você fazia para registrar as suas atividades } \\
\text { de matemática? }\end{array}$ \\
\hline & Se sim, quem mais Ihe incentiva? & 14) Como eram as aulas de matemática? \\
\hline & Qual ano você está estudando? & $\begin{array}{l}\text { 15) Durante as aulas de matemática como você tinha } \\
\text { acesso aos conteúdos que o docente estava } \\
\text { ministrando? }\end{array}$ \\
\hline & $\begin{array}{l}\text { Tipo de escola que você estuda ou } \\
\text { estudou o Ensino Fundamental? }\end{array}$ & $\begin{array}{l}\text { 16) Como você era avaliado nas aulas de } \\
\text { matemática? }\end{array}$ \\
\hline & Você sabe Braille? & $\begin{array}{l}\text { 17)E (era) utilizado algum recurso diferenciado para } \\
\text { ensinar matemática a você? }\end{array}$ \\
\hline & $\begin{array}{l}\text { Você conseguia compreender os } \\
\text { assuntos ensinados de matemática? }\end{array}$ & 18) Se sim, quais? \\
\hline & $\begin{array}{l}\text { Qual era a sua maior dificuldade em } \\
\text { aprender Matemática? }\end{array}$ & $\begin{array}{l}\text { 19) Para você, os materiais concretos ajudam durante } \\
\text { as aulas de matemática? }\end{array}$ \\
\hline & $\begin{array}{l}\text { Você tinha acompanhamento fora da } \\
\text { escola para ajudar no processo de } \\
\text { aprendizagem de matemática? }\end{array}$ & $\begin{array}{l}\text { 20) Dentre os assuntos referentes ao } 6^{\circ} \text { ano citados a } \\
\text { seguir, quais você estudou e qual foi o grau de } \\
\text { aprendizagem? }\end{array}$ \\
\hline
\end{tabular}

Fonte: Roteiro de Entrevista elaborado pelos autores (2017).

A opção por utilizar a entrevista semiestruturada como instrumento de produção de informações deveu-se ao fato de esse tipo de entrevista, segundo Boni e Quaresma (2005), combinar perguntas abertas e fechadas, permitindo que o entrevistado tenha maior possibilidade de discorrer sobre o tema proposto, na qual, o pesquisador deve seguir um conjunto de questões previamente definidas que acontecerão como uma conversa informal, além de não precisar responder por escrito, facilitando deste modo, a participação de pessoas que não sabem ler ou escrever ou no nosso caso, que não podem ver.

As entrevistas ocorreram de setembro a novembro de 2017, numa instituição especializada, da região metropolitana de Belém. Ao todo, 
contamos com a participação de seis estudantes, um do gênero masculino e cinco do gênero feminino, com idades entre 11 e 27 anos.

As entrevistas duraram cerca de 20 a 30 min. Os estudantes ficaram à vontade e livres para falarem das suas experiências. $O$ processo ocorreu de modo tranquilo, em alguns momentos instigamos os estudantes a falarem além do que havia sido perguntado, pois segundo Bourdieu (1999), para se conseguir uma narrativa natural é interessante que o pesquisador faça com que o entrevistado relembre parte da sua vida, suscitando a memória dele algumas vezes se necessário.

\section{Seleção da amostra}

Para participar da entrevista, foram selecionados estudantes cegos que estavam cursando ou já haviam cursado $\circ 6^{\circ}$ ano do ensino fundamental, no ensino regular em escolas de Belém, e que concordaram em participar da pesquisa, concedendo uma entrevista. Todos os participantes, em 2017, recebiam atendimento especializado na instituição supracitada, duas vezes por semana.

\section{Contatos preliminares}

Para termos acesso aos estudantes, fomos antecipadamente à instituição apresentar a proposta de trabalho e solicitar permissão para realização do estudo, bem como solicitamos informações sobre os estudantes cegos. Dialogamos com a coordenadora pedagógica que gentilmente nos recebeu e, de bom grado, nos auxiliou em todo processo. A coordenadora da escola, utilizando as fichas de acompanhamento dos estudantes, selecionou todos aqueles que se encaixavam em nossos critérios, estudantes cegos de salas regulares que em 2017 já tinham cursado ou estavam cursando $\circ 6^{\circ}$ ano do ensino fundamental. Ela nos repassou os nomes, dias e horários dos atendimentos para que pudéssemos entrevistá-los.

A colaboração da coordenadora foi fundamental, uma vez que tinha acesso aos dados da instituição e conhecia cada um dos pais e estudantes que frequentavam o local. Ela nos ajudou também, mediando as 
apresentações, junto aos estudantes e aos responsáveis. À medida que éramos apresentados, explicávamos como funcionaria a pesquisa, o que seria a entrevista e qual seu objetivo, como seria a participação deles no processo e, somente então, solicitávamos o Termo de Consentimento Livre e Esclarecido.

\section{Realização da Entrevista}

As entrevistas ocorreram todas durante o turno da tarde, em sala que permitia o silêncio para a gravação. O trabalho foi no intervalo dos atendimentos educacionais ofertados pela instituição. Em geral, durante a gravação, havia a presença de outras pessoas que acompanhavam o procedimento: responsáveis, coordenadora e até a vice-diretora.

\section{Transcrição}

As entrevistas foram todas transcritas com o auxilio da ferramenta "Digitação por voz" do Gmail. Optamos por não realizar correções gramáticas, ou qualquer outro tipo que alterasse, na íntegra, o que havia sido expressado pelos entrevistados, pois, acreditamos que as suas ideias, pensamentos e experiências deveriam ser retratadas fielmente. Percebemos que a maneira como os estudantes se expressavam, dizia muito sobre sua história, o local de onde vieram e/ou pertenciam, uma vez que, todos nós somos frutos das nossas interações com o outro e com o ambiente. Durante as transcrições, demos espaço para citar as entonações, silêncios, comportamento, gestos, entre outros, apresentadas pelos estudantes, que de acordo com Caiado (2014, p.53), mostram "a multiplicidade de elementos que compõem os significados na linguagem oral.".

Neste artigo, apresentaremos os resultados do eixo Ensino $e$ Aprendizagem em matemática. A etapa da análise das informações foi realizada com base na abordagem qualitativa, pois segundo Minayo (2001), esta trabalha com um universo de significados, atitudes, crenças, entre outros. 


\section{RESULTADOS E ANÁLISE}

Para uma melhor visualização das respostas, as organizamos em quadros, onde a coluna "Respostas" está destinada àquelas dadas de maneira mais objetiva e direta.

\section{Como eram as aulas de matemática}

Neste tópico perguntamos como eram as aulas de matemática nas escolas em que os estudantes frequentaram o $6^{\circ}$ ano. As suas respostas estão no Quadro 2.

QUADRO 2 - Metodologia das aulas

\begin{tabular}{|c|c|}
\hline Estudante & Resposta \\
\hline A & Expositiva \\
\hline B & Expositiva \\
\hline C & Expositiva \\
\hline D & Expositiva \\
\hline E & Expositiva \\
\hline F & Expositiva \\
\hline
\end{tabular}

Fonte: Entrevista (2017)

Todos responderam que as aulas de matemática eram ministradas de forma que os únicos recursos didáticos utilizados eram quadro e pincel, bem como a explicação do assunto. Com base na resposta da estudante C, "O professor não tinha experiência com cegos e por isso não sabia como agir durante as aulas de matemática". Considerando a amostra em foco, verificamos que estudantes cegos de escolas de Belém passam por dificuldades de aprendizagem em matemática, tal qual os estudantes de Roraima, conforme resultados de Uliana (2013).

Ainda em relação às aulas de matemática em escolas de Belém e mediante a resposta da estudante $C$, foi possível verificarmos que quando utilizavam materiais manipulativos em sala, estes eram confeccionados previamente em outro ambiente, para que então, pudessem ser utilizados.

Outro fator que nos chamou a atenção foi os estudantes utilizarem em suas respostas os termos "normal", "iguais às outras aulas", referindo-se a metodologia utilizada pelo professor de matemática para ensinar os 
conteúdos aos cegos e videntes. Os relatos indicam que a prática de aulas expositivas era recorrente e que, dificilmente, era realizado trabalho diferenciado. As atitudes docentes vão de encontro com as orientações de Brasil (2001, p.23), quando adverte que um ensino de matemática pautado apenas em exposições teóricas, sem experiência concreta e significativa, tenderá a desenvolver em qualquer estudante uma atitude desfavorável à assimilação e compreensão dos conteúdos.

\section{Compreensão dos assuntos ensinados}

Sobre o entendimento dos conteúdos matemáticos, perguntamos se os estudantes conseguiam compreender os assuntos ensinados. As respostas encontram-se no Quadro 3.

QUADRO 3- Compreensão de assuntos

\begin{tabular}{|c|c|}
\hline Estudante & Resposta \\
\hline A & Ás vezes \\
\hline B & $\begin{array}{r}\text { As vezes, depende do conteúdo. Quando se trata de gráficos e } \\
\text { geometria espacial não consegue compreender. }\end{array}$ \\
\hline C & Sim \\
\hline D & Sim \\
\hline E & Ás vezes, quando se trata de gráficos não consegue compreender. \\
\hline F & Ás vezes, quando se trata de conteúdos mais visuais não consegue \\
& \\
\hline
\end{tabular}

Fonte: Entrevista (2017).

Das respostas dos estudantes, notamos que todos eles compreendiam, mesmo que um pouco, os assuntos de matemática ensinados, visto que, suas respostas foram "sim" ou "às vezes", destacando que nenhum deles respondeu não compreender. No entanto, durante seus relatos, percebemos que a compreensão ocorria mais de conteúdos que privilegiam os cálculos mentais e o raciocínio lógico, que dos assuntos como geometria espacial e gráficos, os estudantes alegaram ter dificuldade. Isto foi observado por Sviech (2009, p.57), quando verificou que entre as dificuldades encontradas na aprendizagem de matemática por cegos, estão os conteúdos que envolvem a parte visual da matemática, pois, segundo a autora o Braille ajuda bastante, mas não pode reproduzir imagens e desenhos. 
Sviech (2009) apontou que assim como os estudantes entrevistados tiveram dificuldade de compreensão dos assuntos, o professor também admitiu problemas em ensinar os estudantes cegos. Sviech (2009, p.63) diz que a maior dificuldade em ensinar matemática, está na parte da geometria analítica, uma vez que o estudante não possuía a visão e o professor tinha que trabalhar questões do espaço e figuras.

\section{Dificuldade em aprender matemática}

Nesta pergunta, pretendíamos saber qual era a maior dificuldade para os estudantes cegos aprenderem matemática na escola.

Quadro 4 - Dificuldade em aprender matemática

\begin{tabular}{|c|c|}
\hline Estudante & Resposta \\
\hline A & Fórmulas e metodologia do professor \\
\hline B & Visualização de imagens \\
\hline C & Visualização de imagens \\
\hline D & Consegue entender bem \\
\hline E & Metodologia do Professor \\
\hline F & Contas e a Metodologia do Professor \\
\hline
\end{tabular}

Ainda das respostas dos estudantes, verificarmos que as maiores dificuldades enfrentadas na sala de aula, não eram relacionadas aos assuntos matemáticos e sim a metodologia adotada pelos professores, uma vez que, três deles relataram claramente sobre a metodologia do professor e os outros dois falaram de conteúdos mais visuais, como o estudo de gráficos e figuras, o que para nós, pode ser também uma consequência da metodologia utilizada para ensinar tais assuntos. Logo, uma das maiores dificuldades dos estudantes em aprenderem matemática, estava na metodologia adotada pelos professores, a qual pode ser consequência da formação que estes não receberam para trabalhar em turmas inclusivas, como foi apresentado por Dias e Sá (2017) e Uliana (2015).

A falta de formação específica para ensinar matemática para estudantes cegos, em turmas inclusivas, tem se refletido nas metodologias inadequadas adotadas e, consequentemente, na pouca aprendizagem dos 
estudantes, o que acaba prejudicando a autoestima deles, e até o seu relacionamento em sala de aula. Precisamos ficar atentos para algumas ações docentes, que de acordo com Cerva Filho (2014) também influenciam na aprendizagem da matemática, a exemplo do posicionamento corporal, de expressões e verbalismo.

\section{Acompanhamento para aprender matemática for da escola}

$\mathrm{Na}$ questão em foco, pretendíamos saber se os estudantes cegos possuíam algum acompanhamento fora da escola, em se tratando do processo de aprendizagem de matemática.

Quadro 5 - Acompanhamento

\begin{tabular}{|c|c|}
\hline Estudante & Resposta \\
\hline A & Sim \\
\hline B & Não \\
\hline C & Sim \\
\hline D & Dúvida \\
\hline E & Sim \\
\hline F & Sim \\
\hline
\end{tabular}

As respostas dos estudantes indicam que, a maior parte deles, tinha acompanhamento fora da escola, para ajudar na fixação das aprendizagens em matemática. Ainda relacionado a este fato, perguntamos onde acontecia o acompanhamento, suas respostas foram:

QUADRO 6- Local do acompanhamento

\begin{tabular}{|c|c|}
\hline Estudante & Resposta \\
\hline A & Sala de Recursos Multifuncionais e em Casa \\
\hline B & Não realizava acompanhamento \\
\hline C & Instituição Especializada e Internet \\
\hline D & Instituição Especializada e Família \\
\hline E & AEE e Instituição Especializada \\
\hline F & Instituição Especializada \\
\hline
\end{tabular}

Fonte: Entrevista (2017).

As respostas indicam que os locais mais utilizados para 0 acompanhamentos foram: a instituição especializada da região e dentro de suas próprias casas com a ajuda dos parentes. Desta forma, percebemos 
que os estudantes recorriam a atendimento especializado fora da escola que os ajudasse na disciplina matemática, o que nem sempre conseguiam. Este fato ocorre segundo Moraes, Vieira e Santos (2016), devido às escolas regulares não terem: estrutura física adequada; equipamentos para a preparação de materiais adequados; professores especializados; textos escritos em Braille, entre outros.

Diferentemente, as escolas especializadas costumam ter todos os requisitos necessários para ensinar estudantes com deficiência, neste caso os cegos. Desta maneira, concordamos com Moraes, Vieira e Santos (2016) quando relatam que a escola regular deveria estar preparada para receber os estudantes na perspectiva da educação inclusiva e não deixar esta tarefa apenas a cargo das escolas especializadas.

\section{Dificuldade nas Tarefas de matemática}

Com esta pergunta pretendíamos saber quais eram as tarefas consideradas como as mais difíceis para os estudantes cegos realizarem durante as aulas de matemática.

QUADRO 7 - Dificuldade das Tarefas das aulas

\begin{tabular}{|c|c|}
\hline Dificuldade durante as aulas de matemática & Valor Absoluto \\
\hline Registrar o que esta/estava sendo ensinado & 2 \\
\hline Construir as imagens mentalmente das figuras, gráficos & 2 \\
\hline O tempo disponibilizado para resolver as atividades & 2 \\
\hline Compreender a Explicação do Professor & 1 \\
\hline
\end{tabular}

Fonte: Entrevista (2017).

A partir das informações, verificamos que as tarefas mais difíceis para os estudantes realizarem em sala de aula eram: registro das atividades; construção mental das imagens; realizar as tarefas dentro do tempo disponibilizado e, conforme a resposta da estudante E: "A explicação do professor que é difícil de acompanhar".

Estas dificuldades foram registradas em Uliana (2013), relatando que os estudantes inseridos no ensino regular não consideravam as aulas de forma ativa, pois não eram dadas as condições para as aprendizagens dos cegos. 
A autora elencou carências do ponto de vista estrutural das escolas de Roraima, que também se assemelhavam com dificuldades presentes no contexto de Belém como: falta de materiais pedagógicos apropriados, para dar suporte às aulas de matemática, para estudantes cegos; estrutura inapropriada das escolas; currículo que respeite os seus tempos de aprendizagens e professores capacitados para atender as necessidades dos estudantes cegos.

\section{Registro e Acesso das atividades}

A questão referente a este subeixo, tratava sobre como os estudantes cegos faziam para registrarem suas atividades de matemática em sala de aula. A partir de suas respostas elaboramos o quadro a seguir:

Quadro 8 - O registro das atividades

\begin{tabular}{|c|c|}
\hline Estudante & Resposta \\
\hline A & Alguém escreve para ele ou é passado para o Braille \\
\hline B & Gravava, mas agora não faz mais o registro. \\
\hline C & Acesso antes de o assunto ser ministrado e usava gravador \\
\hline D & A mãe escreve no caderno \\
\hline E & O irmão escreve no caderno \\
\hline F & Em Braille \\
\hline
\end{tabular}

Fonte: Entrevista (2017).

Por meio dos relatos, observamos que predominava o fato de o estudante cego não conseguir fazer seu próprio registro das atividades de matemática, dependendo de alguém que o fazia para ele, principalmente, parentes. Dois estudantes relataram o uso do Braille, no entanto, dentre eles, apenas um fazia este registro, uma vez que o outro apenas lia o material feito em Braille pelo professor itinerante.

Talvez o fato de os estudantes cegos não utilizarem tanto a escrita Braille, como registro na sala de aula, fosse devido à mesma "gastar" mais caracteres para escrever do que se deseja, uma vez que na escrita em Braille, existe um sinal para indicar letra maiúscula, quando for número, entre outros, que na escrita em tinta não são necessários, já que seus usuários conseguem visualizar se a palavra inicia com letra maiúscula, se é número e 
assim por diante, tal como foi explicado no estudo de Anjos (2016), o qual apontou que este aumento de caracteres influência de forma negativa o aprendizado do aluno cego em matemática, visto que a leitura e a escrita em Braille se tornam mais cansativas e lentas.

Quanto ao gravador, o uso deste não era recorrente, sendo utilizado apenas em alguns momentos. Pois dentre os seis estudantes cegos entrevistados, apenas um deles, de fato, fazia o registro das atividades de matemática, por meio de gravação, tendo maior autonomia durante as aulas. O fato de cinco estudantes indicarem situação de dependência para a realização de seus registros e atividades é algo preocupante, devido comprometer e retardar a autonomia desses estudantes, bem como o próprio processo de inclusão de pessoas com necessidades especiais.

\section{Acesso aos conteúdos de matemática}

Em relação à maneira como o estudante cego tinha acesso aos conteúdos de matemática que o professor (a) ministrava em sala, obtemos os seguintes relatos:

Quadro 9 - Acesso aos conteúdos

\begin{tabular}{|c|c|}
\hline Estudante & Resposta \\
\hline A & Livro e caderno \\
\hline B & Livro e Dosvox \\
\hline C & Xerox dos cadernos dos colegas e \\
& Dosvox \\
\hline D & Caderno \\
\hline E & Caderno \\
\hline F & Folhas com as anotações em Braille \\
\hline
\end{tabular}

Fonte: Entrevista (2017).

Com base nesses relatos, percebemos que a maneira mais ut ilizada para os estudantes terem acesso aos conteúdos de matemática, era o caderno, o que condiz com as respostas da pergunta anterior, uma vez que, a forma de registro mais utilizada era a escrita feita por terceiros, em seus cadernos que, posteriormente, eram acessados para estudo e resolução de exercícios, mas, novamente, o aluno cego recorria à ajuda de outrem. As 
outras maneiras de acesso citadas por eles foram: o programa de computador Dosvox e o livro didático, sendo que este último, não estava adaptado para o Braille, situação que requeria do estudante a necessidade da ajuda de terceiros para estudar em seu domicilio, fato que consideramos, mais uma vez, limitador da capacidade dos estudantes de progredirem em seus estudos, de modo autônomo, uma vez que continuavam dependentes da presença e disponibilidade de pessoas do seu convívio para auxilia-los em suas necessidades de aprendizagem.

Ao unirmos as respostas dos estudantes sobre como chegavam até eles os conhecimentos matemáticos, e sermos informados sobre os recursos mais utilizados terem sido o caderno e o livro didático, concluímos que os estudantes cegos tiveram acesso aos conhecimentos mais por meio da escuta, ou seja, pelo sentido da audição. Situação confirmada por docentes ouvidos na investigação de Dias e Sá (2017), quando aludiram que o acesso aos assuntos matemáticos, estava sendo realizado, em sua maioria, apenas pelo sentido da audição, seguido do Braille.

\section{Avaliação nas aulas de Matemática}

O quadro a seguir nos dá indícios de quais instrumentos eram utilizados pelos professores de matemática para avaliarem as aprendizagens dos estudantes cegos.

Quadro 10 - Modos de avaliação

\begin{tabular}{|c|c|}
\hline Estudante & Resposta \\
\hline A & Prova oral \\
\hline B & Prova Oral \\
\hline C & Prova e trabalho \\
\hline D & Prova Oral \\
\hline E & Prova Oral e trabalho \\
\hline F & Prova Oral e trabalho \\
\hline
\end{tabular}

Fonte: Entrevista (2017).

Com base nas respostas, verificamos que os estudantes cegos eram avaliados por meio do método tradicional que é a prova, neste caso, a prova oral. A maioria deles nos disse que realizavam a avaliação fora da sala 
regular, para que barulhos externos não influenciassem no andamento da avaliação. Durante a prova, um professor lia as questões para que eles pudessem dizer qual era a resposta correta, neste caso, alguns estudantes citaram questões de múltipla escolha, mas outros relataram que, quando necessário, explicavam para o professor, etapa por etapa, que deveria ser seguida para a resolução das questões. Metade dos estudantes ouvidos também indicou a realização de trabalhos escolares, como parte das avaliações, além de alguns materiais manipuláveis, conforme foi citado pelo estudante A.

A fala da estudante $C$ referindo-se a como era o processo avaliativo de seu professor, chamou nossa atenção: "ele me passava quatro questões porque ai ele ficava preocupado que fossem muitas questões...". A afirmação nos fez refletir que, ainda nos dias atuais, existem professores que vinculam a capacidade de aprendizagem dos estudantes, a sua deficiência física ou limitação. O professor em questão passava somente quatro questões da prova, por acreditar que, se fossem muitas, a estudante não conseguiria responder ou ter bons resultados, atitude que causava estranheza à própria discente.

Infelizmente, ainda são muitos os professores que por suas limitações de pensamento e falta de formação, não conseguem perceber o potencial de aprendizagem e desejo de superação existente na maioria das pessoas com deficiência. Calore (2007) afirma que os cegos são difusores de conhecimentos, práticas e comportamentos socioculturais que são determinados por uma limitação sensorial, mas que nem por isso devem ser considerados ineficientes ou desprezíveis, pelo contrário, eles têm o direito a uma sobrevivência, equivalente aos não deficientes, o que inclui um processo educacional comum que respeite suas especificidades.

Retornando a forma equivocada, adotada pelo professor da estudante $C$, no momento da avaliação, consideramos que, para respeitar as especificidades de um aluno cego, não precisa o professor ter pena de sua condição e, por isso, lhes passar tarefas mais fáceis que para os demais estudantes. Muito pelo contrário, ele deve disponibilizar amplas 
oportunidades para que os estudantes possam mostrar suas habilidades e competências diante dos conteúdos a serem aprendidos. Afinal, como diz Teixeira e Nunes (2014, p.74): "Precisamos acredit ar na capacidade do aluno e na nossa capacidade de lidar com os diversos quadros existentes na sala de aula. O nosso desafio está em aprendermos a trabalhar pedagogicamente com a diversidade.".

\section{Materiais e Recursos específicos para trabalhar com estudantes cegos}

Na questão, pretendíamos saber se nas aulas da matemática eram utilizados recursos diferenciados para o ensino dos estudantes cegos

Quadro 11 - Recursos nas aulas

\begin{tabular}{|c|c|}
\hline Estudante & Resposta \\
\hline A & Sim \\
\hline B & Não \\
\hline C & Sim \\
\hline D & Na maioria das vezes \\
\hline E & Não \\
\hline F & Apenas uma vez \\
\hline
\end{tabular}

Ao observarmos as respostas, verificamos que houve um empate, e que $\circ$ fato de os professores não utilizarem recursos para $\circ$ ensino de matemática, era prática pedagógica recorrente dentre os docentes dos estudantes cegos. Também percebemos que o uso ou não dos recursos, não, necessariamente, estava vinculada a rede em que a escola pertencia se pública ou privada, visto que os estudantes $A$ e $C$ que disseram utilizar recursos diferenciados ondem estudavam, ambos eram oriundos de escolas públicas estaduais. Em contrapartida, os estudantes B e E disseram não usar recursos, sendo que o primeiro estudava em uma escola privada e 0 segundo em uma pública estadual. Os estudantes $D$ e F também matriculados em escolas públicas do estado disseram que utilizavam os recursos necessários para aprendizagem algumas vezes. Deste modo, observamos que não eram o local ou a infraestrutura que influência na utilização de recursos diferenciados. 
A experiência enquanto docentes e os resultados de pesquisas, como algumas elencadas por nós nesse trabalho, fortalecem nossa convicção da necessidade de utilizarmos mais recorrentemente recursos diferenciados no ensino de matemática, principalmente, quando se trata do ensino para estudantes cegos, em classes regulares. Não precisam, necessariamente, serem recursos muito elaborados ou de alto custo, basta que sejam adaptadas à deficiência do estudante, neste caso, a visão. Segundo Sá (2013) está adaptação deveria ocorrer por meio de descrição, informação tátil, auditiva, olfativa ou qualquer outra referência que favoreça a aprendizagem e para tal deverá ser planejada com antecedência, principalmente, quando se tratar de atividades predominantemente visuais.

Para saber quais são os recursos diferenciados, perguntamos aos estudantes e obtivemos as seguintes respostas.

Quadro 12 - Recursos utilizados

\begin{tabular}{|c|l|}
\hline Estudante & \multicolumn{1}{|c|}{ Resposta } \\
\hline A & $\begin{array}{l}\text { Materiais em alto relevo; soroban; máquina Braille; material concreto; } \\
\text { Computador. }\end{array}$ \\
\hline B & Não utilizava recursos \\
\hline C & Reglete; Computador; Braille. \\
\hline D & "Tela" \\
\hline E & Não utilizava recursos \\
\hline F & Material concreto \\
\hline
\end{tabular}

Após análise, observamos que os recursos mais utilizados com eles eram: o material concreto, o computador e o Braille, seja ele na máquina ou com o uso da reglete. Os resultados assemelham-se aos achados de Dias e Sá (2017), em que os autores relataram que os recursos mais utilizados pelos professores para ensinam matemática aos estudantes deficientes visuais, eram: Materiais concretos, sorobã/ábaco, softwares especializados e a máquina Braille. Nossa pesquisa confirmou o resultado dos autores, visto que, os estudantes cegos ouvidos neste estudo, também indicaram os mesmos recursos como mais utilizados. Na busca de algo em comum entre os materiais concretos usados nas aulas, notamos que todos remetiam para 
outra fonte de entrada de informação que não fosse à visão, nest e caso as mais empregadas eram o tato e a audição.

\section{Materiais concretos nas aulas de matemática}

Em relação a este tópico, perguntamos para os estudantes cegos se eles achavam que os materiais concretos ajudavam durante as aulas de matemática.

Quadro 13 - Opinião sobre os materiais concretos

\begin{tabular}{|c|c|}
\hline Estudante & Resposta \\
\hline A & Sim \\
\hline B & Sim \\
\hline C & Sim \\
\hline D & Sim \\
\hline E & Sim \\
\hline F & Sim \\
\hline
\end{tabular}

Fonte: Entrevista (2017).

Unanimemente, eles afirmaram que os materiais concretos podiam ajudar nas aulas de matemática, pois, auxiliam na construção das imagens mentais, como bem foi dito pela estudante B: "[...] consegui ter a memória fotográfica do que eu tateei e consegui responder à questão". Sendo assim, apesar de nem todos utilizarem materiais concretos durante as aulas de matemática, como já vimos, estudantes e professores acreditavam que o uso pode ajudar no processo de ensino e aprendizagem, como relatado em Fernandes e Healy (2007), Monteiro et al (2013) e Vieira e Silva (2007) que defenderam o uso de materiais concretos para favorecer o processo de aprendizagem os estudantes videntes ou cegos, visto que, se utilizam da "sensação tátil" para "tornar" o ensino de matemática mais palpável.

Da resposta da estudante $E$ percebemos preocupação em relação ao uso de materiais concretos sem a ajuda de um terceiro. Segundo a aluna, estes materiais ajudavam na aprendizagem de matemática, mas precisaria de alguém para acompanhar e ajudar durante o uso em sala de aula, o que de acordo com ela não ocorreu. Tal relato indica a necessidade de formação continuada dos docentes, por meio de cursos e oficinas que os 
ensine a lidar com esses materiais mais específicos e de momentos de elaboração de atividades com materiais que possam ser realizadas dentro de sala de aula, preferencialmente, conjuntamente com seus colegas de classe.

\section{Grau de dificuldade de conteúdos matemáticos junto a estudantes cegos}

Neste item buscamos saber quais assuntos que normalmente são trabalhados no $6^{\circ}$ ano do ensino fundamental e que os estudantes cegos, com base em suas histórias de vida, consideravam os mais difíceis para aprender.

A partir das suas respostas foi elaborado o quadro a seguir. Para facilitar o reconhecimento, decidimos destacar os maiores valores percentuais obtidos em cada assunto, com cores diferentes, conforme suas categorias: fácil - verde; regular - amarelo; difícil - vermelho.

Quadro 14 - Grau de dificuldade

\begin{tabular}{|c|c|c|c|c|c|c|c|c|c|c|}
\hline \multirow{3}{*}{$\begin{array}{c}\text { Eixo } \\
\text { Temático }\end{array}$} & \multirow[t]{3}{*}{ Assuntos } & \multirow{2}{*}{\multicolumn{3}{|c|}{ Estudou este assunto? }} & \multicolumn{6}{|c|}{ Grau de dificuldade para aprender (\%) } \\
\hline & & & & & \multirow[t]{2}{*}{ MF } & \multirow[t]{2}{*}{$\mathbf{F}$} & \multirow[t]{2}{*}{$\mathbf{R}$} & \multirow[t]{2}{*}{ D } & \multirow[t]{2}{*}{ MD } & \multirow{2}{*}{$\begin{array}{c}\text { Não } \\
\text { Informou }\end{array}$} \\
\hline & & Sim & Não & $\begin{array}{l}\text { Não } \\
\text { lembro }\end{array}$ & & & & & & \\
\hline \multirow{15}{*}{$\begin{array}{c}\text { Números } \\
\text { e } \\
\text { Operaçõ } \\
\text { es }\end{array}$} & Adição com reserva & 100 & & & 16 & 50 & 17 & 17 & 0 & 0 \\
\hline & Adição sem reserva & 100 & & & 33 & 67 & 0 & 0 & 0 & 0 \\
\hline & Subtração com reserva & 100 & & & 0 & 67 & 16 & 17 & 0 & 0 \\
\hline & Subtração sem reserva & 100 & & & 17 & 83 & 0 & 0 & 0 & 0 \\
\hline & Multiplicação & 100 & & & 0 & 83 & 17 & 0 & 0 & 0 \\
\hline & Divisão exata & 100 & & & 33 & 33 & 17 & 17 & 0 & 0 \\
\hline & Divisão não exata & 100 & & & 0 & 0 & 50 & 33 & 17 & 0 \\
\hline & $\begin{array}{l}\text { Problemas envolvendo } \\
\text { as } 4 \text { operações }\end{array}$ & 100 & & & 0 & 33 & 50 & 0 & 17 & 0 \\
\hline & Expressões Numéricas & 100 & & & 0 & 16 & 17 & 50 & 17 & 0 \\
\hline & Conceito de fração & 100 & & & 0 & 50 & 17 & 33 & 0 & 0 \\
\hline & $\begin{array}{ll}\text { Simplificação } & \text { de } \\
\text { fração } & \end{array}$ & 83 & & 17 & 0 & 17 & 33 & 17 & 16 & 17 \\
\hline & $\begin{array}{ll}\text { Comparação } & \text { de } \\
\text { frações } & \end{array}$ & 83 & & 17 & 0 & 0 & 66 & 17 & 0 & 17 \\
\hline & $\begin{array}{l}\text { Adição de frações de } \\
\text { mesmo denominador }\end{array}$ & 83 & & 17 & 0 & 33 & 50 & 0 & 0 & 17 \\
\hline & $\begin{array}{l}\text { Adição de frações de } \\
\text { denominadores } \\
\text { diferentes }\end{array}$ & 67 & & 33 & 0 & 33 & 17 & 17 & 0 & 33 \\
\hline & $\begin{array}{ll}\text { Subtração de } & \text { frações } \\
\text { de } & \text { mesmo } \\
\text { denominador } & \end{array}$ & 67 & 16 & 17 & 0 & 33 & 17 & 17 & 0 & 33 \\
\hline
\end{tabular}




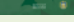

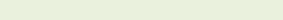

\begin{tabular}{|c|c|c|c|c|c|c|c|c|c|c|}
\hline \multirow[t]{14}{*}{ 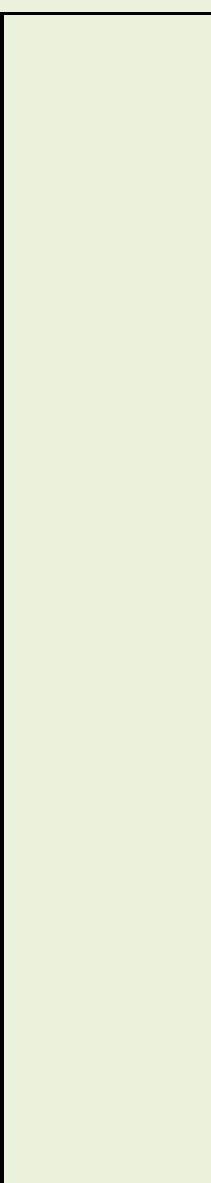 } & $\begin{array}{l}\text { Subtração de frações } \\
\text { com denominadores } \\
\text { diferentes }\end{array}$ & 50 & & 50 & 0 & 0 & 33 & 17 & 0 & 50 \\
\hline & $\begin{array}{l}\text { Potenciação } \\
\text { Radiciação }\end{array}$ & 100 & & & 17 & 33 & 17 & 33 & 0 & 0 \\
\hline & $\begin{array}{l}\text { Resolver problemas em } \\
\text { que se conhece o todo } \\
\text { e se deseja as partes }\end{array}$ & 17 & 16 & 67 & 0 & 17 & 0 & 0 & 0 & 83 \\
\hline & $\begin{array}{l}\text { Resolver problemas em } \\
\text { que se conhece uma } \\
\text { parte e se deseja o } \\
\text { todo }\end{array}$ & 67 & & 33 & 0 & 0 & 67 & 0 & 0 & 33 \\
\hline & $\begin{array}{l}\text { Resolver problemas em } \\
\text { que se conhece uma } \\
\text { parte e se deseja } \\
\text { conhecer a outra parte }\end{array}$ & 67 & 16 & 17 & 0 & 17 & 50 & 0 & 0 & 33 \\
\hline & Números Decimais & 100 & & & 0 & 50 & 33 & 17 & 0 & 0 \\
\hline & Adição de decimais & 100 & & & 0 & 67 & 16 & 0 & 17 & 0 \\
\hline & Subtração de decimais & 100 & & & 17 & 50 & 17 & 16 & 0 & 0 \\
\hline & $\begin{array}{l}\text { Multiplicação de } \\
\text { decimais }\end{array}$ & 83 & & 17 & 16 & 17 & 50 & 0 & 0 & 17 \\
\hline & Divisão de decimais & 67 & & 33 & 0 & 33 & 34 & 0 & 0 & 33 \\
\hline & Números primos & 83 & & 17 & 0 & 33 & 50 & 0 & 0 & 17 \\
\hline & $\begin{array}{l}\text { Fatoração em números } \\
\text { primos }\end{array}$ & 67 & 16 & 17 & 0 & 0 & 50 & 17 & 0 & 33 \\
\hline & $\mathrm{MMC}$ & 67 & & 33 & 0 & 33 & 17 & 17 & 0 & 33 \\
\hline & $\mathrm{MDC}$ & 83 & & 17 & 0 & 16 & 50 & 0 & 17 & 17 \\
\hline \multirow{6}{*}{$\begin{array}{l}\text { Espaço e } \\
\text { Forma }\end{array}$} & Figuras Geométricas & 100 & & & 0 & 83 & 17 & 0 & 0 & 0 \\
\hline & Retas & 83 & & 17 & 0 & 33 & 33 & 17 & 0 & 17 \\
\hline & Segmento de retas & 67 & 16 & 17 & 0 & 17 & 33 & 17 & 0 & 33 \\
\hline & Retas no plano & 50 & 17 & 33 & 0 & 17 & 16 & 17 & 0 & 50 \\
\hline & Ângulos & 83 & & 17 & 0 & 16 & 67 & 0 & 0 & 17 \\
\hline & Polígonos & 50 & 17 & 33 & 0 & 33 & 0 & 17 & 0 & 50 \\
\hline \multirow{5}{*}{$\begin{array}{l}\text { Grandeza } \\
\text { s e } \\
\text { Medidas }\end{array}$} & $\begin{array}{ll}\text { Medida } & \text { de } \\
\text { comprimento } & \end{array}$ & 100 & & & 0 & 33 & 67 & 0 & 0 & 0 \\
\hline & Medida de área & 100 & & & 0 & 83 & 17 & 0 & 0 & 0 \\
\hline & Medida de volume & 100 & & & 0 & 67 & 16 & 17 & 0 & 0 \\
\hline & $\begin{array}{ll}\text { Medida } & \text { de } \\
\text { Capacidade } & \end{array}$ & 50 & & 50 & 0 & 17 & 16 & 17 & 0 & 50 \\
\hline & Medida de tempo & 100 & & & 17 & 50 & 33 & 0 & 0 & \\
\hline \multirow{6}{*}{$\begin{array}{l}\text { Tratament } \\
\text { o da } \\
\text { Informaçã } \\
\text { o }\end{array}$} & Tipos de gráficos & 67 & & 33 & 0 & 17 & 33 & 0 & 17 & 33 \\
\hline & Construção de Tabelas & 67 & 33 & & 0 & 17 & 33 & 0 & 17 & 33 \\
\hline & Leitura de Tabelas & 67 & 16 & 17 & 0 & 33 & 17 & 0 & 17 & 33 \\
\hline & Construção de Gráficos & 83 & 17 & & 0 & 33 & 33 & 0 & 17 & 17 \\
\hline & Leitura de Gráficos & 83 & 17 & & 0 & 50 & 16 & 0 & 17 & 17 \\
\hline & Média Aritmética & 83 & & 17 & 17 & 33 & 33 & 0 & 0 & 17 \\
\hline
\end{tabular}

Fonte: Entrevista (2017).

Assim, entre os assuntos considerados como mais difíceis em Números e Operações, temos: Expressões Numéricas; Divisão não exata; Simplificação de Fração; Potenciação e Radiciação. No eixo Espaço e Forma os assuntos 
foram: Ângulos; Retas e Segmento de retas. Em Grandezas e Medidas foram: Medida de comprimento e Medida de Capacidade. No eixo Trat amento da Informação foram: Tipos de Gráficos; Construção de Tabelas e Construção de Gráficos.

A partir das informações analisadas, observamos que a opinião dos estudantes em relação aos assuntos de matemática mais difíceis do $6^{\circ}$ ano para aprenderem, foram também apontados nos estudos que consultaram professores que ensinavam matemática para deficientes visuais como Dias e Sá (2017), Costa et al (2010) e Silva e Santos (2013) o que nos revela que estas dificuldades não são recentes e são de conhecimento de ambas as partes, professor e aluno.

\section{CONSIDERAÇÕES FINAIS}

A finalização desse trabalho nos permitiu conhecer percepções de seis estudantes cegos incluídos/inseridos em turmas regulares, com foco em como acontecia o processo de ensino e aprendizagem da matemática, no $6^{\circ}$ ano do Ensino Fundamental, identificando quais assuntos eram considerados pela amostra como os mais difíceis para o estudante cego aprender.

Considerando nosso objetivo de pesquisa que foi realizar um diagnóstico do processo de ensino e aprendizagem de matemática no $6^{\circ}$ ano para estudantes cegos de Belém do Pará, e retomando aos resultados pertinentes aos eixos Ensino e Aprendizagem em Matemática foipossivel concluir que:

Sobre Características das aulas de matemática, eram predominantemente expositivas, mesmo assim, todos compreendiam, ainda que em parte, as matérias ensinadas. Segundo relatos dos estudantes, a compreensão dava-se mais dos assuntos que privilegiam os cálculos mentais e o raciocínio lógico. Já quando se tratava de assuntos com maior apelo visual isso implicava na necessidade de materiais de apoio e de metodologia apropriada para facilitarem a aprendizagem dos estudantes cegos, coisa que raramente eles tinham. 
Quanto ao Registro e Acesso, concluímos que apesar dos esforços pessoais dos estudantes para aprender, todos explicitaram depender de terceiros para ajuda-los nos registros das atividades escolares. O fato ocorria nas aulas de matemática, mas também, nas outras disciplinas, indicando que a autonomia dos estudantes cegos quanto as suas rotinas escolares ainda estava muito longe de acontecer.

Relativo ao modo como os estudantes cegos eram avaliados, predominaram enquanto instrumentos, as provas orais, seguidas de trabalhos escolares. O resultado indica limitações na prática dos professores dos estudantes cegos, em relação a não adoção de avaliações mais processuais e dinâmicas.

Sobre a utilização de Materiais concretos e Recursos, os resultados evidenciaram ausências de recursos específicos para atender às necessidades sensórias e motoras dos estudantes, fato que pode indicar problemas de infraestrutura da escola, como também, falta de sensibilidade dos professores de atenderem às especificidades que os estudantes cegos têm na hora de criar seus esquemas mentais dos assuntos, em que o sentido da visão é o primeiro a ser acionado, no momento das exposições didáticas.

Os estudantes cegos sabiam ou estavam aprendendo o Braille, no entanto, nas escolas dificilmente utilizavam esta escrita em suas atividades, devido os professores não saberem trabalhar com ela. Como agravante, ainda temos o fato de que livros didáticos dos estudantes não serem traduzidos para o Braille. Para nós foi surpreendente e, ao mesmo tempo, decepcionante saber que dificuldades com ausência de materiais específicos para estudantes cegos tanto são sentidas por estudantes matriculados em escolas públicas, quanto particulares de Belém. O fato nos faz refletir que está sendo subtraído dos cegos o direito de aprendizagem, tal qual é disponibilizado aos estudantes videntes.

Os resultados da pesquisa nos permitiu refletir que, apesar dos avanços no campo das políticas públicas e legislações para o atendimento de pessoas com deficiência, assim como, da ampla divulgação do direito a inclusão, muito ainda são os desafios vividos por estudantes, professores e 
instituições. As dificuldades em aprender/ensinar matemática para estudantes cegos persistem, de modo que, pesquisas como esta, podem contribuir para maior conhecimento dos problemas detectados $e$, principalmente, incentivar educadores a adotarem outras posturas didáticas. Vale destacar que, o fato de haver assuntos não considerados como os mais difíceis para estudantes cegos, não significa dizer que estes não precisam de uma atenção didática, uma vez que fazem parte do currículo e precisarão ser trabalhados em sala de aula.

Por fim, julgamos serem necessárias novas pesquisas relacionadas à área da inclusão, especialmente, de estudantes cegos, nas classes regulares, de modo a ampliar a amostra. Isso poderá trazer à tona, aspectos não conhecidos sobre as dificuldades e superações que pessoas cegas passam para ter direito a educação. Torna-se necessário, refletirmos ainda mais sobre os caminhos do ensino inclusivo, para buscarmos em conjunto, soluções ou medidas que colaborem para que dificuldades como as apresentadas pelos estudantes cegos de Belém, não se perpetuem além do tempo e sejam banalizadas no contexto escolar. Finalmente, são necessárias mais pesquisas voltadas para criação de materiais alternativos, auxiliares do trabalho pedagógico, dos conteúdos específicos de matemática, sobretudo, aqueles que os estudantes cegos afirmam ter mais dificuldades de aprendizagem.

\section{REFERÊNCIAS}

ANJOS, D. Z. dos. Código matemático unificado: da definição às diferenças semióticas na conversão da tinta ao Braille. In: ENCONTRO NACIONALDE EDUCAÇÃ O MATEMÁTICA, XII, 2016, São Paulo. Anais... São Paulo:Universidade Cruzeiro do Sul, 2016.Disponível em: $<$ http://www.sbembrasil.org.br>. Acesso em: 16 jan. 2018.

BRASIL. Ministério da Educação. Resolução CNE/CEB N², de 11 de setembro de 2001. Brasilia, DF, 2001.5p.

BOURDIEU, P.A miséria do mundo. Tradução: AZEVEDO, M. S. S. $3^{a}$ edição. Petrópolis: Vozes, 1999. 
BONI, V.; QUARESMA, S. J. Aprendendo a entrevistar: como fazer entrevistas em Ciências Sociais. Revista Eletrônica dos Pós-Graduandos em Sociologia Política da UFSC, n. 1 (3), p.68-80, jan.-jul., 2005.

CAIADO, K. R. M. Aluno com deficiência visual na escola: lembranças e depoimentos. 3. ed. Campinas, SP: Autores Associados, 2014. 147p.

CALORE, A. C. de O. A Etnomatemática e a deficiência visual: um caminho para a inclusão cultural. In: ENCONTRO NACIONAL DE EDUCAÇÃO MATEMÁTICA, IX, 2007, Belo Horizonte. Anais... Belo Horizonte: Universidade de Belo Horizonte, 2007. Disponível em: <http://www.sbembrasil.org.br>. A cesso em: 16 jan. 2018.

CERVA FILHO, O. A. Educação Matemática e o Aluno Cego: ação docente frente à inclusão. Dissertação (Mestrado em Ensino de Ciências e Matemática)- Universidade Luterana do Brasil, Canoas, 2014. 135p.

COSTA, M. I.S. da; SÁ, P. F. de; MELO, M. de L. S; ARAUJO, S. P. F. Dificuldades do ensino de matemática para cegos segundo a opinião de docentes.In: ENCONTRO NA CIONAL DE EDUCA ÇÃO MATEMÁTICA, X, 2010, Ilhéus/ BA. Anais... Ilhéus: 2010. Disponível em: <http://www.sbembrasil.org.br>A cesso em: 16 jan. 2018.

DIAS, S. da C.; SÁ, P. F. de. A visão de docentes de Belém do Pará sobre as dificuldades do ensino de matemática para deficientes visuais. In: CONGRESSO INTERNACIONAL DE ENSINO DA MATEMÁTICA, VII, 2017, UlbraCanoas/RS. Anais... Canoas: Universidade Luterana do Brasil, 2017. Disponível em: <http://www.conferencias.ulbra.br/index.php/ciem/vii>. A cesso em: 22 fev. 2018.

FERNANDES, S. H. A. A.; HEALY, L. As Concepções de alunos cegos para os conceitos de área e perímetro. In: ENCONTRO NACIONAL DE EDUCAÇÃO MATEMÁTICA, IX, 2007, Belo Horizonte. Anais... Belo Horizonte: Universidade de Belo Horizonte, 2007. Disponível em: <http://www.sbembrasil.org.br>Acesso em: 16 jan. 2018.

MINAYO, M. C. de S. (Org.). Pesquisa social: teoria, método e criatividade. Petrópolis: Vozes, 2001.

MORAES, M. E. L. de.; VIEIRA, S. de C. A.; SANTOS, F. M. dos. A leitura em Braille: apropriação de matemática para aluno adulto com cegueira adquirida como elevador de autoestima. In: ENCONTRO NACIONALDE EDUCAÇÃ O MATEMÁTICA, XII, 2016, São Paulo. Anais... São Paulo:

Universidade Cruzeiro do Sul, 2016. Disponível em:

<http://www.sbembrasil.org.br>A cesso em: 16 jan. 2018.

MONTEIRO, A. D.; SILVA, C. M. da.; COSTA, L. B. da.; PEREIRA, R. dos S. G. O uso de materiais adaptados no ensino da matemática para o aluno cego e com baixa visão. In: ENCONTRO NACIONAL DE EDUCAÇÃO MATEMÁTICA, XI, 
2013, Curitiba/PR. Anais... Curitiba: Pontifícia Universidade Católica do Paraná, 2013. Disponível em: <http://www.sbembrasil.org.br>Acesso em: 16 jan. 2018.

SÁ, E. D. de. Atendimento Educacional Especializado para alunos cegos e com baixa visão. In: MANTOAN, M. T. E. (Org.). O desafio das diferenças nas escolas. 5 ed. Petrópolis, RJ: Vozes, 2013.152p.

SVIECH, V. de F. O ensino de matemática na perspectiva do aluno cego: um estudo de caso. Sinop/MT, 2009. Disponível em:

<http://sinop.unemat.br/site/>. A cesso em: 22 fev. 2018.

SILVA, M. de P. F. da; SANTOS, N. S. P. S. As dificuldades do ensino de matemática para cegos segundo docentes de Vigia de Nazaré. 2013.

Trabalho de Conclusão de Curso (Licenciatura em Matemática)Universidade do Estado do Pará. Vigia/PA, 2013.

TEIXEIRA, J.; NUNES, L. Avaliação inclusiva: a diversidade reconhecida e valorizada. 2 ed. Rio de Janeiro: Wak Editora, 2014. 128p.

ULIANA, M.R. A inclusão de alunos cegos nas aulas de matemática das escolas públicas estaduais de Rondônia. In: ENCONTRO NACIONALDE EDUCAÇÃ O MATEMÁTICA, XI, 2013, Curitiba/PR. Anais...Curitiba: Pontifícia Universidade Católica do Paraná, 2013. Disponível em:

<http://www.sbembrasil.org.br>A cesso em: 16 jan. 2018.

ULIANA, M.R. Formação de Professores de Matemática, Física e Química na perspectiva da inclusão de estudantes com deficiência visual: análise de uma intervenção realizada em Rondônia. 2015.314p. Tese (Doutorado em Educação em Ciências e Matemática) - Universidade Federal de Mato Grosso, Rede Amazônica de Educação em Ciências e Matemática. Cuiabá, 2015.

VIEIRA, S. S.; SILVA, F. H. S. da. Flexibilizando a Geometria na Educação Inclusiva dos Deficientes Visuais: uma proposta de atividades. In: ENCONTRO NA CIONAL DE EDUCA ÇÃO MATEMÁTICA, IX, 2007, Belo Horizonte. Anais... Belo Horizonte: Universidade de Belo Horizonte, 2013. Disponível em: <http://www.sbembrasil.org.br>A cesso em: 16 jan. 2018.

Recebido em: 21 de setembro de 2018. Aprovado em: 23 de agosto de 2018. 